treatment' advocated by Greene. ${ }^{4}$ Some attempt to summarise the method seems in order. My concern also stems from the naive statement of the original model. No attempt is made to articulate clearly the theoretical basis for including variables in the model. In defence of the author I should emphasise that this was claimed to be a preliminary analysis. Greene also indicated preference for a study which could have adopted an experimental design and in which randomisation of clients would be undertaken to assess whether there were any substitution effects. This was apparently not possible. The use of a quasi-experimental design in which the level of informal support before and after a client is referred to CSS was measured might have provided a more solid data set on which to build econometric models. I would have accepted the usefulness of this study in the current debate had the author identified the limitations of the method and the study more forcefully.

\title{
NOTES
}

I Bayley, M. Mental Handicap and Community Care. Routledge and Kegan Paul, London, 1973. Department of Health and Social Security, Ageing in the United Kingdom. DHSS, London, 1982.

2 See, for example, Wicks, $M$ and Rossiter, C. Crisis or challenge? Family care, social policy and elderly people. Study Commission on the Family, London, 1982.

3 Brody, E. M., Johnsen, P. T., Fulcomer, M. C. and Lang, A. M. Women's changing roles and help to elderly parents: attitudes of three generations of women. Journal of Gerontology, $\mathbf{3}^{8}$ (1983), 606.

4 Theil, H. Principles of Econometrics. John Wiley \& Sons, New York, 1971.

\section{Social Work and Social}

\section{Administration}

\section{Heather Roughton}

Peter Saxby and David Jeffery, In a strange land, Social Work Today, $15(1983), 16,17$.

This brief article reports on two surveys carried out on behalf of West Devon Social Services Department as part of an investigation into the problem of caring for confused elderly residents of Part III homes.

The first survey involved interviews with management and care staff of six homes, together with assessment of residents' abilities. The most commonly reported problems were incontinence, wandering and aggression, and staff expressed concern about the hostility frequently expressed by the more lucid and alert residents towards their disoriented 
colleagues. The issue of integration or segregation of such residents was frequently raised.

The second study contains the results of a questionnaire survey of staff attitudes towards confused residents, and staff views on their role in helping such residents. In the nine homes surveyed, all grades of staff emerge as having attitudes that are caring, realistic and optimistic about change. Their opinions about what can be done to reduce confused behaviour accord with generally recognised therapeutic practice. The authors rightly caution that it is difficult to know how far these attitudes are translated into staff's performance without a direct study of staff and resident interaction, but there is recent evidence that this is frequently at odds with the aspirations of staff. Saxby and Jeffery also point out that staff may also find emphasis on therapeutic measures at odds with a philosophy of residential care which stresses the importance of a caring, homely atmosphere.

The article concludes by identifying implications for staff training, and proposes further evaluation of different teaching methods to promote desired staff behaviours.

R. C. Taylor and E. G. Ford, The elderly at risk: a critical examination of commonly identified risk groups, Journal of the Royal College of General Practitioners, 33 (1983), 699-705.

This longitudinal survey into coping in later life is being conducted by the MRC Medical Sociology Unit at Aberdeen, and on the evidence of this first stage, promises rich data on the life style and experiences of the older generation.

The paper reports on interviews with 6 I 9 over-6os living in Aberdeen. The data were analysed identifying i i subcategories of the population considered to be 'at risk' - namely the very old, recently widowed, the divorced and separated, socially isolated, those who have never married, the childless, those in class $\mathrm{V}$, those with a weekly income below Supplementary Benefit level, and two groups experiencing transition, i.e. those who have recently (in the last 2 years) moved house, or been discharged from hospital.

Nineteen variables relating to health, psychological status, social activity, availability of family and friends, income and housing, provide a profile of the eleven groups.

Those who emerge as particularly at risk are those who have experienced hospital care of have moved home in the last two years. This is despite higher than average availability of family members, and 
high levels of personal support, which suggests that for those individuals who score worse than the sample as a whole in terms of health or psychological functioning, family support alone may not be sufficient. Also in this 'highest risk' category are the very old ( $15 \%$ of the sample), and the divorced/separated who are mainly to be found in the younger age groups.

Dee Jones, Christina Victor and Norman Vetter, Carers of the elderly in the community. Joumal of the Royal College of General Practitioners, 33 (1983), 707-710.

This study examines the nature of help which the over-7os receive with tasks of everyday living. The sample is drawn from a large urban general practice in South Wales, and 657 patients were interviewed to assess their physical, mental and social well-being, and explore their need for assistance. The most commonly mentioned tasks for which help was needed were the washing and ironing of clothes and travelling by bus. A third of main helpers were themselves over 65 , and one in ten over 75. Daughters were named most frequently as the main helper, followed by spouses, thus confirming the finding of other studies of carers that the family bears the major part of the burden of caring for the elderly. Only a minority of helpers worked for a living, but five (four women, one man) had given up work to look after their relatives.

The home help service was the only significant source of help from the statutory or voluntary service, and almost exclusively was directed to those living alone. The family carers were often unaided, and over time suffered from social isolation, which exacerbated the vulnerability of the elderly should their carer become ill or otherwise unable to cope.

Thus we have yet more evidence of the neglect of family carers by the formal services, and testimony of the continued importance of family support for the vast majority of elderly and disabled people.

\section{Psychology and Psychiatry}

\section{Jeffrey Garland}

Larner, Stuart L. . and Leeming, James T. The work of a clinical psychologist in the care of the elderly, Age and Ageing, 13 (1984), 29-33.

Close to tears and very angry, the 86-year-old woman in a geriatric rehabilitation ward told me her grievances. It was almost in passing that 